\title{
Quantum Energy Calculations of Technological Parameters of Electromagnetic Impact on Heavy Hydrocarbons
}

\author{
Alim Feizrakhmanovich Kemalov ${ }^{1}$, Ruslan Alimovich Kemalov ${ }^{1}$, Abdrafikova Ilmira Maratovna ${ }^{1} \&$ Valiev \\ Dinar Zinnurovich ${ }^{1}$ \\ ${ }^{1}$ Kazan (Volga region) Federal University, Kazan, Russian Federation \\ Correspondence: Alim Feizrakhmanovich Kemalov, Kazan (Volga region) Federal University, 8, Kremlevskaya \\ street, Kazan, 420008, Russian Federation.
}

Received: June 27, 2014

doi:10.5539/mas.v9n4p312
Accepted: August 6, $2014 \quad$ Online Published: March 30, 2015

URL: http://dx.doi.org/10.5539/mas.v9n4p312

\begin{abstract}
According to modern conceptualizations oil forms complex dispersed system containing disperse phase formed of high molecular compounds: long-straight-chained hydrocarbons or asphaltene-resin compounds with high concentration of heteroelements and metals and dispersion media formed of hydrocarbons of less molecular weight. These days, along with traditional methods for oil treating, the new ones are appearing aimed at transforming of high molecular compounds into smaller ones. And the role of magnetic, electromagnetic, acoustic field's investigations on the properties of the oil is growing. For the proper impact on oil it is necessary to conduct deep investigations of the oil components structure changes. In this regard, considerable interest, first of all, is quantum-chemical analysis of the relationship "carbon-carbon (C-C) and carbon - hydrogen (C-H), which is conducted not at the molecular but at the atomic level. So the purpose of the work was to conduct the quantum energy calculations of the parameters of electromagnetic impact on heavy hydrocarbons. With the changes in temperature of the system, the vibration frequency of atomic bonds will be also changed. Consequently, in any attempt to impact on petroleum components with using external excitation sources, should be taken into account the temperature factor and must be established connection between the source of impact and temperature. In this paper additional opportunities to specify the resonant excitation temperature of oil and the relationship between temperature and frequency characteristics of the atoms and molecules were identified.
\end{abstract}

Keywords: pulsed NMR, bitumen-polymer binder, structural-group composition, roof waterproofing materials, thermoplastic resins

\section{Introduction}

Impact on petroleum and petroleum products in various ways to alter their physicochemical properties, fractional composition in a favorable direction is the essence of technological operations, which allow, for example, to increase the yield of the most valuable components of petroleum - motor oil, to improve the quality of the oil fraction, to prepare high-quality raw materials for transportation and further processing, as well as improving the physical and chemical properties of fuels. Along with traditional methods of impact to petroleum and petroleum products to improve their physical and chemical properties, fractional composition, there are also methods of wave impact, which include magnetic, electromagnetic, acoustic ways of processing, and other fields on the properties of oil (Inada, et al., 2005; Domínguez, et al., 2007; Venkatesh Kamath, et al., 2011; Kemalov, et al., 2012).

Thus, was patented a method of increasing the yield of light oil fractions by processing with the rotary-pulsation acoustic device (RPAD), hydrodynamic generators which creates high-frequency oscillations, which leads treated fluid to the active (excited) state. A feature of these devices is the impact of petroleum a wide range of frequencies.

Since petroleum is a very complex mixture of different classes of hydrocarbons, heteroatom compounds, and they are in complex intermolecular bonds, forming a dispersed system with complex internal structure, we can expect a wide range of vibrational spectrum of itself the petroleum. It follows that for purposeful impact on petroleum components is necessary to choose an object of impact. In this regard, considerable interest, first of all, is quantum-chemical analysis of the relationship "carbon-carbon $(\mathrm{C}-\mathrm{C})$ and carbon-hydrogen $(\mathrm{C}-\mathrm{H})$ ", which is conducted not at the molecular but at the atomic level (Mukhutdinov, et al., 2011; Kemalov, et al., 2013; 
Kemalov and Kemalov, 2013; Alam and Ahmad, 2014; Arjunan, et al., 2014; Gordon, et al., 2014; Karlický, et al., 2014; Mahdizadeh and Goharshadi, 2014). This analysis is especially important in connection with the fact that thermal degradation, catalytic bead, and many other ways to impact on the oil feedstock are based on the excitation, rupture and formation of these bonds (Guilbert, et al., 2014; Kaminski, et al., 2001).

In addition, with the changes in temperature of the system, the vibration frequency of atomic bonds will be also changed. Consequently, in any attempt to impact on petroleum components with using external excitation sources, should be taken into account the temperature factor and must be established connection between the source of impact and temperature (Fischer and Radom, 2001).

The determination of laws governing the behavior of hydrogen and other atoms at the resonant frequencies and the relationship of these frequencies with the temperature can become an additional and main way on the effectiveness of existing methods of impact on the oil feedstock (Göltl, 2014).

In a carbon-hydrogen mixture, the prevailing compounds are " $\mathrm{C}-\mathrm{C}$ " and " $\mathrm{C}-\mathrm{H}$ ". To change physical-chemical properties of oil, the latter should be influenced upon. As the rule, such influence is produced by means of heating a hydrocarbon mixture (oil) and its fractionation.

But what is the temperature range, in which it would be possible to obtain the maximum effect? And what else should be done to raise the efficiency of acting upon oil, to increase the output of light oil products (diesel, kerosene, benzene fractions).

\section{Materials and Methods}

As it is known from practice, the principal reserve is acting upon heavy molecules within the range of temperatures from $350^{\circ} \mathrm{C}$ to $500^{\circ} \mathrm{C}$ and higher (to make these molecules disintegrate into lighter ones, which brings about increase of the output of light oil products). In practice, oil-processing enterprises use an expensive technique (multiple vacuum distillation). However, there is a more efficient method, which does not require expensive installations and allows obtaining up to $70 \%$ light oil products (of the supplied amount of oil) with just one atmospheric column used. The essence of this method lies in the knowledge of behavior of hydrogen atoms at resonant frequencies (temperatures), when (with minimum energy input «from outside») the $« \mathrm{C}-\mathrm{H} »$ bonds are broken. As a result, the number of light molecules is increased, which gives an increase of the output of light oil products.

So, to affect heavy molecules in the temperature range above $350^{\circ} \mathrm{C}$, we use the resonant characteristic of hydrogen.

Taking hydrogen $\mathrm{H}$ for the basis, in the " $121 \times 121$ " matrix we shall have:

$$
\begin{aligned}
& T_{\text {ionization } 1 H}{ }^{1}=58564 K, \quad E_{\text {ionization } 1}{ }_{1}^{1}=13.619 \mathrm{eV} ; \\
& T_{\text {ionization } 1^{H}}=58291^{\circ} \mathrm{C}, E_{\text {ionization } 1^{H}}=13.555 \mathrm{eV}
\end{aligned}
$$

The resonant temperature characteristics are determined as follows:

$$
\begin{aligned}
& T_{\text {resonance }}(K)=\frac{58564}{121}=484 \mathrm{~K} ; \\
& T_{\text {resonance }}\left({ }^{\circ} \mathrm{C}\right)=\frac{58291}{121}=481.74^{\circ} \mathrm{C} .
\end{aligned}
$$

The minimum temperature (per one quantum-state) will correspondingly be equal to $4 \mathrm{~K}$ or $3.98{ }^{\circ} \mathrm{C}$. Let us take temperature in ${ }^{\circ} \mathrm{C}$ for the basis. The matrix of hydrogen ${ }_{1}^{1} \mathrm{H}$ will look as presented in Figure 1, while the matrix of carbon ${ }_{6}^{12} \mathrm{C}$ reduced to the single coordinates is presented in Figure 2.

Therefore, applying the rule of displacement of the electron shells (see above), we can see that on the first electron shell of the atom of carbon (in the scale of the " $121 \times 121$ " matrix on the sixth quantum-state for hydrogen ${ }_{1}^{1} \mathrm{H}$ ) the temperature is $58291^{\circ} \mathrm{C} / z=58291 / 6=9715^{\circ} \mathrm{C}$ 


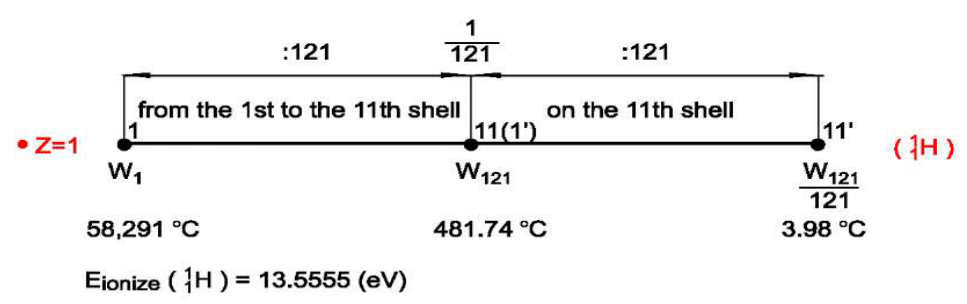

Figure 1. The hydrogen matrix $\left({ }_{1}^{1} H\right)$. Temperature in ${ }^{\circ} \mathrm{C}$ is taken for the basis.

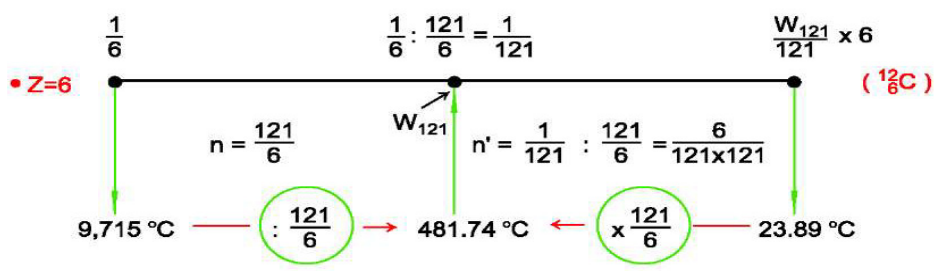

Figure 2. The carbon matrix $\left({ }_{1}^{1} H\right)$ brought into the "single coordinates".

These explanations are sufficient for understanding. Further calculations are made in a relatively simple way.

\section{Results}

The basis of the calculation may be either energy potential E, to be further converted in temperature through the formula $E=2.32549 \square 0^{-4} \square T^{\circ}$ or immediately the temperature itself $\left(T_{\text {ionization }}\right)$.

Let us adopt for calculation the simplest option, i.e. calculation through $T_{\text {ionization }{ }_{1} H}=58564 \mathrm{~K}$.

Let us calculate resonant frequencies and temperature range of the " $\mathrm{C}-\mathrm{H}$ " compound. As the two atoms ${ }_{6}^{12} \mathrm{C}{ }_{6}^{12} \mathrm{C}$ and ${ }_{1}^{1} \mathrm{H}$ are interconnected, they affect upon each other, therefore the resonant temperature will have the range from $T_{\min }$ to $T_{\max }$.

Let us begin our calculation from carbon ${ }_{6}^{12} \mathrm{C}{ }_{6}^{12} \mathrm{C}$, as it will define the main characteristics (of the bond) due to the fact its charge and weight are six times as big as those of hydrogen ${ }_{1}^{1} H$, and, correspondingly, it will define the maximum constituent of equilibrium radiation.

As the temperature of ionization of hydrogen $\left(T_{\text {ionization }{ }_{1} H}\right)$ is equal to $58564 \mathrm{~K}=13.619 \mathrm{eV} /\left(2.32549 \square 0^{-4} \mathrm{eV} /\right.$ degree $)$, all other atoms with charge $\mathrm{z}$ (sum of oscillators) will have the temperature of equilibrium radiation on the first own electron shell in the " $121 \times 121$ " matrix $z$ times lower.

For carbon ${ }_{6}^{12} \mathrm{C}, \mathrm{z}=6$, therefore the temperature on the first shell of the atom of carbon (in the scale of the matrix of hydrogen) will be six times lower than $T_{\text {ionization } 1^{H}}$.

To proceed from $\mathrm{K}$ to ${ }^{\circ} \mathrm{C}$, let us apply the approach $T_{\text {ionization }{ }_{1} H}=T_{\text {ionization }}(K)-273$, then 
$T_{\text {ionization } 1} 1^{1}\left({ }^{\circ} \mathrm{C}\right)=58564 \mathrm{~K}-273=58291{ }^{\circ} \mathrm{C} \quad$ (see above).

As ${ }_{6}^{12} \mathrm{C}$ has charge $\mathrm{z}=6, T_{\text {ionization } 1} 1^{1}\left({ }^{\circ} \mathrm{C}\right)$ of the atom of carbon, with $\mathrm{n}=1$ (when the atom is unexcited) will be equal to:

$$
T_{\text {ionization }}{ }_{6}^{12} \mathrm{C}\left({ }^{\mathrm{C}} \mathrm{C}\right)=58291^{\circ} \mathrm{C} / 6=9715^{\circ} \mathrm{C} \text {. }
$$

\section{Discussion}

According to the theory of the state of thermal equilibrium and equilibrium thermal radiation, if a charge (number of oscillators) increases with a factor equal to $k, \frac{z=6}{z=1}=\mathrm{k}=6$, based on the formula $E=h \sqsubset v$, frequency $v$ should also increase with a factor of $k$ (as $\mathrm{h}$ - Planck's constant has a fixed value).

At the same time, $v=R / n^{2}$, where $\mathrm{R}$ is the Rydberg's constant, which is also fixed. Correspondingly, to make frequency increase with a factor of $k$ (compared to hydrogen ${ }_{1}^{1} H, k=z$ times), the number of $\mathrm{n}^{2}$ (the number of an electron shell) should become $\mathrm{\kappa}$ or $\mathrm{z}$ as low (that is another variant confirming that the adopted approach to quantization (displacement) of electron shells is true) (Sitkoff, et al., 1994; Petrangeli, 2006; Shao, et al., 2006; Spooner, et al., 2014.).

Therefore, for the atom of carbon ${ }_{6}^{12} \mathrm{C}{ }_{6}^{12} \mathrm{C}$, the resonant frequency, corresponding to the resonant frequency of the atom of hydrogen in the scale of the " $121 \times 121$ " matrix, will be on the shell (in the quantum-state) $n^{2} / z=\frac{121}{6}=20.166 \ldots$. We have taken $n^{2}=121$, i.e. the resonant frequency of the atom of hydrogen will be found on the eleventh shell, or on the first sublevel of the eleventh shell $\left(W_{121}=E_{\text {ionization }} / 121\right)$.

As we know, $n^{2} / z$ is the number of quantum-states $\left(20.166 \square 481.74^{\circ} \mathrm{C}=9715^{\circ} \mathrm{C}\right)$, while the square root of $n^{2} / z$ is the number of shell (from the first shell to the eleventh shell). Hence, for the atom of carbon ${ }_{6}^{12} C n$ will be equal to:

$$
n=\sqrt{n^{2} / z}=\sqrt{20.166}=4.49 .
$$

However, the number of a shell may only be integer (Kaminski, et al., 2001; Arjunan, et al., 2014; Gordon, et al., 2014), correspondingly, resonant temperatures for carbon ${ }_{6}^{12} \mathrm{C}$ in the " $121 \times 121$ " matrix will be on integer numbers to 4.49 , i.e. 4 and $5: \mathrm{n}_{\text {resonance } 1}=4, \mathrm{n}_{\text {resonance } 2}=5$.

In the formula of permissible values of the internal energy of the atom $E_{n}=\frac{-m_{e} \sqsubset e^{4} \sqsubset z^{2}}{2 \sqsubset n^{2}}$ (with $\mathrm{n}=1,2,3 \ldots 11$ ) was applied the approach which uses the "single coordinates": $z^{2}=z_{1} \cdot z_{2}\left(z_{1}=z_{2}\right)$, where $z_{1}$ is used with $T_{\text {ionization }}$ ${ }_{1}^{1} H / z$, and $z_{2}-$ with $n^{2} / z$. I.e. $z_{1}$ is used for the state of thermal equilibrium, and $z_{2}$ is used for equilibrium thermal radiation.

Let us calculate temperatures for $n=4$ and $n=5$ of the atom of carbon:

$$
\begin{aligned}
& \mathrm{T}_{4}\left({ }^{\circ} \mathrm{C}\right) \text { for }{ }_{6}^{12} \mathrm{C}=9715 / n^{2}=9715 / 16=607.2^{\circ} \mathrm{C} ; \\
& \mathrm{T}_{5}\left({ }^{\circ} \mathrm{C}\right) \text { for } \quad{ }_{6}^{12} \mathrm{C}=9715 / n^{2}=9715 / 25=388.6 .
\end{aligned}
$$


Here, the resonant temperature is calculated as follows:

$$
T_{\text {resonance }}{ }_{6}^{12} \mathrm{C}=9715 / 20.166=481.74^{\circ} \mathrm{C} \text {. }
$$

However, this resonant temperature $\left(481.74{ }^{\circ} \mathrm{C}\right)$ does not fall to an integer number of the electron shell (4.49), therefore, it will only appear (be enabled) due to the external factors, rather than the atom of carbon itself. This will be the very case, when we shall excite the $\mathrm{C}-\mathrm{H}$ bond through the resonant constituent of hydrogen, acting upon it $\left(481.74{ }^{\circ} \mathrm{C}\right)$. This $\mathrm{T}_{\text {resonance }}$ is used in the invention to achieve an increase of the output of light oil products (Guilbert, et al., 2014; Inada, et al., 2005)

So, what the result can we get with $\mathrm{n}=4$ and $\mathrm{n}=5$ ?

$$
\mathrm{T}_{4}=607.2^{\circ} \mathrm{C} ; \mathrm{T}_{5}=388.6^{\circ} \mathrm{C} \text {. }
$$

However, we have to determine the range of temperatures for the $\mathrm{C}-\mathrm{H}$ bond; knowing that the nucleus charge and weight of hydrogen ${ }_{1}^{1} \mathrm{H}$ are six times smaller than those of carbon ${ }_{6}^{12} \mathrm{C}$, let us determine the percentage ratio between these numbers from the relation $z_{1}^{1} / z^{12}{ }_{6} C=\frac{1}{6}$.

Since we have two oscillators taken together, temperature T, which is common for the equilibrium state and equilibrium radiation for ${ }_{6}^{12} \mathrm{C}$ will be changed (decreased) in the $\mathrm{C}-\mathrm{H}$ bond by $\left(\frac{1}{6}\right) 100=16.66$ and the following temperature range will be formed:

$$
\begin{gathered}
\text { 1. } T_{4 \max }=607.2^{\circ} \mathrm{C} ; \\
T_{4 \min }=607.2^{\circ} \mathrm{C}-16.6=506^{\circ} \mathrm{C} ; \\
\text { 2. } T_{5 \max }=388.6^{\circ} \mathrm{C} ; \\
T_{5 \max }=388.6^{\circ} \mathrm{C}-16.6=323.9^{\circ} \mathrm{C} .
\end{gathered}
$$

It can be seen from these calculations, that they are based on the above-mentioned materials.

To make the reasoning more illustrative, and to compare the obtained results to the practical ones, Figure 3 and Figure 4 are supplemented presenting an oil diagram. Devon oil is very light (Figure 3), therefore its lower resonant temperatures range is moved to the left (closer to zero) to a great extent than in case with another heavier oils.

When acting upon the hydrocarbon mixture through hydrogen $\left({ }_{1}^{1} H\right)$ - his resonant frequency:

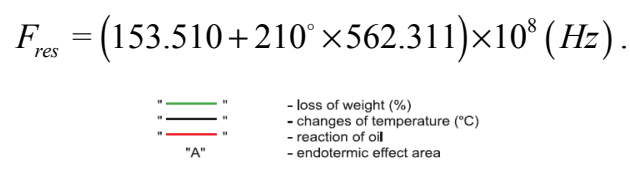

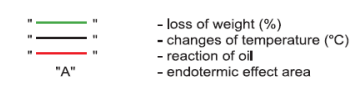

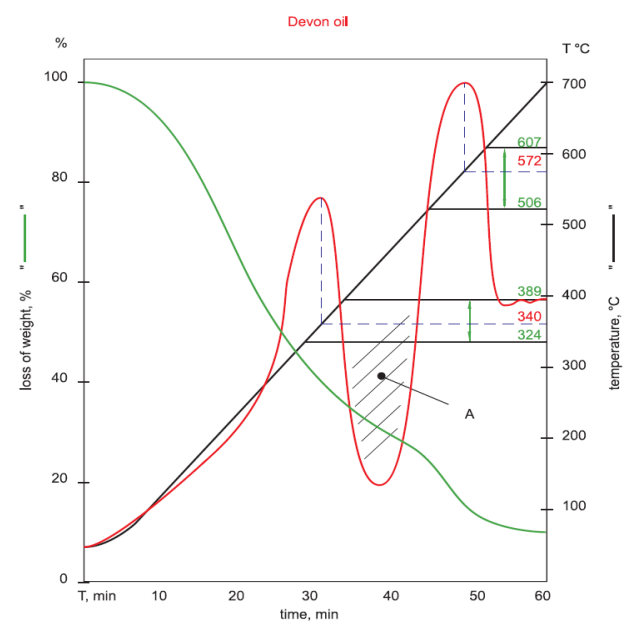

Figure 3. Annex to the calculation of "C-H" compositions resonant temperatures for hydrocarbon mixture (for oil) 


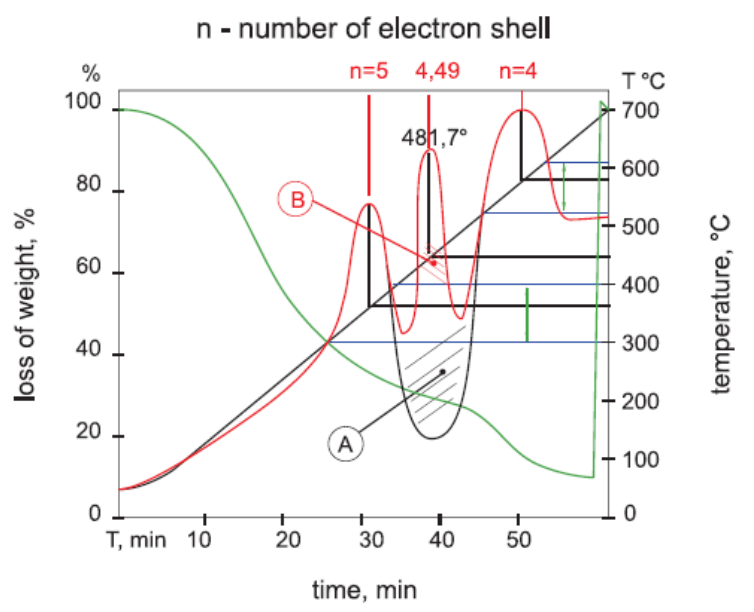

Figure 4. Diagram of excitations of hydrocarbon liquid (oil) in the stock container produced through excitation of hydrogen

When acting upon the hydrocarbon mixture through ${ }_{1}^{1} \mathrm{H}$, we have not zone A (see Figure 3), i.e. the zone of endothermic effect, which is constantly present in the unexcited mixture or cracking zone, but zone B (see Figure 4), i.e. the zone of exothermal effect arising in the hydrocarbon mixture after the latter has been affected through hydrogen ${ }_{1}^{1} H$, made in the laboratory conditions with an instrument, and showing the relation between the oil weight and its temperature. Resonant temperature ranges of oil (which match almost exactly the above-obtained calculated results) can be clearly seen in the diagram.

Deviations are common, but they are not very significant and are characterized by oil quality (its purity), i.e. content of sulfur, paraffin, asphalt-resin substances, etc.

A specimen under investigation was heated up to $700^{\circ} \mathrm{C}$, therefore the calculated temperatures are presented in the graph in an illustrative and complete way (throughout the whole temperature range).

\section{Conclusions}

In this paper were identified additional opportunities to specify the resonant excitation temperature of oil and the relationship between temperature and frequency characteristics of the atoms and molecules. Since the calculations are done for hydrogen protons, for more carbonated structures it would be much more complicated. Because of the latter, further studies are needed including in calculation the data obtained by instrumental methods, which could take into account with a high accuracy heteroatom-containing and metal compounds. As a result, it may be possible to include the matrices of heteroelements and metals into the quantum-chemical calculations, considering the asymmetry and defects of their molecular structures.

\section{References}

Alam, M. J., \& Ahmad, S. (2014). Quantum chemical and spectroscopic investigations of 3-methyladenine. Spectrochimica Acta - Part A: Molecular and Biomolecular Spectroscopy, 128, 653-664. http://dx.doi.org/10.1016/j.saa.2014.02.170

Arjunan, V., Thillai Govindaraja, S., Jose, S. P., \& Mohan, S. (2014). DFT simulation, quantum chemical electronic structure, spectroscopic and structure-activity investigations of 2-benzothiazole acetonitrile. Spectrochimica Acta - Part A: Molecular and Biomolecular Spectroscopy, 128, 22-36. http://dx.doi.org/10.1016/j.saa.2014.02.187.

Domínguez, A., Menéndez, J. A., Fernández, Y., Pis, J. J., Nabais, J. M. V., Carrott, P. J. M., \& Carrott, M. M. L. R. (2007). Conventional and microwave induced pyrolysis of coffee hulls for the production of a hydrogen rich fuel gas. Journal of Analytical and Applied Pyrolysis, 79(1-2 spec. iss.), 128-135. http://dx.doi.org/10.1016/j.jaap.2006.08.003.

Fischer, H., \& Radom, L. (2001). Factors controlling the addition of carbon-centered radicals to alkenes - An 
experimental and theoretical perspective (Review). Angewandte Chemie - International Edition, 40(8), 1340-1371. http://dx.doi.org/10.1002/1521-3773(20010417)40:8<1340::AID-ANIE1340>3.0.CO;2-\#.

Göltl, F., Houriez, C., Guitou, M., Chambaud, G., \& Sautet, P. (2014). Importance of a nonlocal description of electron-electron interactions in modeling the dissociative adsorption of $\mathrm{H}_{2}$ on $\mathrm{Cu}$ (100). Journal of Physical Chemistry C, 118(10), 5374-5382. http://dx.doi.org/10.1021/jp4118634.

Gordon, D. F., Hafizi, B., \& Helle, M. H. (2014). Solution of relativistic quantum optics problems using clusters of graphical processing units. Journal of Computational Physics, 267, 50-62. http://dx.doi.org/10.1016/j.jcp.2014.02.028.

Guilbert, A. A. Y., Frost, J. M., Agostinelli, T., Pires, E., Lilliu, S., MacDonald, J. E., \& Nelson, J. (2014). Influence of bridging atom and side chains on the structure and crystallinity of cyclopentadithiophene-benzothiadiazole polymers. Chemistry of Materials, 26(2), 1226-1233. http://dx.doi.org/10.1021/cm403410w

Inada, M., Tsujimoto, H., Eguchi, Y., Enomoto, N., \& Hojo, J. (2005). Microwave-assisted zeolite synthesis from coal fly ash in hydrothermal process. Fuel, 84(12-13), 1482-1486. http://dx.doi.org/10.1016/j.fuel.2005.02.002

Kaminski, G. A., Friesner, R. A., Tirado-Rives, J., \& Jorgensen, W. L. (2001). Evaluation and reparametrization of the OPLS-AA force field for proteins via comparison with accurate quantum chemical calculations on peptides. Journal of Physical Chemistry B, 105(28), 6474-6487. http://dx.doi.org/10.1021/jp003919d

Karlický, F., Lepetit, B., \& Lemoine, D. (2014). Quantum modelling of hydrogen chemisorption on graphene and graphite. Journal of Chemical Physics, 140(12). http://dx.doi.org/10.1063/1.4867995

Kemalov, A. F., \& Kemalov, R. A. (2013). Structural and Dynamic Studies of Naphtha Crude Residue with Different Chemical Nature. World Applied Sciences Journal (Special Issue on Techniques and Technologies), $22,16-22$.

Kemalov, A. F., Kemalov, R. A., \& Valiev, D. Z. (2013). Study of the structure of complex structural units of heavy oil from Zyuzeevskaya field by NMR relaxometry and rheological studies. Oil Industry, 2, 63-65.

Kemalov, R. A., Kemalov, A. F., \& Valiev, D. Z. (2012). Thermodynamics of viscous flow activation and structural-dynamic analysis of high-viscosity oil with ultrasonication. Oil industry, 12, 100-103.

Mahdizadeh, S. J., \& Goharshadi, E. K. (2014). Hydrogen storage on silicon, carbon, and silicon carbide nanotubes: A combined quantum mechanics and grand canonical Monte Carlo simulation study. $\begin{array}{lllll}\text { International Journal of Hydrogen } & \text { Energy, }\end{array}$ http://dx.doi.org/10.1016/j.ijhydene.2013.11.037

Mukhutdinov, E. A., Mukhutdinov, A. A., Gubaidullin, A. T., Krivolapov, D. B., \& Litvinov, I. A. (2011). Crystal structure of N-phenyl-N'-isopropylp-phenylenediamine. Journal of Structural Chemistry, 52(1), C. 206-207. http://dx.doi.org/10.1134/S002247661101029X

Petrangeli, G. (2006). Nuclear Safety. Elsevier Ltd, Amsterdam, Netherlands. ISBN: 978-075066723-4, pp: 430.

Shao, Y., Molnar, L. F., Jung, Y., Kussmann, J., Ochsenfeld, C., Brown, S. T., ... Head-Gordon, M. et al. (2006). Advances in methods and algorithms in a modern quantum chemistry program package (Review). Physical Chemistry Chemical Physics, 8(27), 3172-3191. http://dx.doi.org/10.1039/b517914a

Sitkoff, D., Sharp, K. A., \& Honig, B. (1994). Accurate calculation of hydration free energies using macroscopic solvent models. Journal of Physical Chemistry, 98(7), 1978-1988. ISSN: 00223654.

Spooner, J., Yanciw, B., Wiebe, B., \& Weinberg, N. (2014). Reaction profiles and energy surfaces of compressed species. Journal of Physical Chemistry A, 118(4), 765-777. http://dx.doi.org/10.1021/jp410496t

Venkatesh Kamath, H., Regupathi, I., \& Saidutta, M. B. (2011). Optimization of two step karanja biodiesel synthesis under microwave irradiation. Fuel Processing Technology, 92(1), 100-105. http://dx.doi.org/10.1016/j.fuproc.2010.09.003

\section{Copyrights}

Copyright for this article is retained by the author(s), with first publication rights granted to the journal.

This is an open-access article distributed under the terms and conditions of the Creative Commons Attribution license (http://creativecommons.org/licenses/by/3.0/). 